\title{
As nanotecnologias no meio ambiente do trabalho: a precaução para equacionar os riscos do trabalhador.
}

Nanotechnologies in environmental work: precaution to equate the risks for worker.

\section{Raquel Von Hohendorff}

Advogada, Médica Veterinária. Especialista em Direito do Trabalho. Mestranda do Programa de Pós-Graduação em Direito da Universidade do Vale do Rio dos Sinos (UNISINOS). São Leopoldo, Brasil.

\section{Wilson Engelmann}

Professor. Doutor em Direito. Programa de Pós-Graduação em Direito da Universidade do Vale do Rio dos Sinos (UNISINOS). São Leopoldo, Brasil.

\section{Maria de Lourdes Oshiro}

Farmacêutica/Bioquímica. Professora. Doutora em Ciências da Saúde. Universidade Católica Dom Bosco e Programa de Pós-Graduação em Saúde Coletiva da Escola de Saúde Pública da Secretaria de Saúde do Mato Grosso do Sul. Campo Grande, Brasil.

Resumo: A ampliação do uso das nanotecnologias é uma inovação que vem ocorrendo no setor de produção, trazendo conjuntamente preocupações acerca dos riscos à saúde e ao meio ambiente. O potencial às nanopartículas parece infinito, com novas aplicações nas mais diferentes áreas, e muito ainda a ser desvendado e explorado. Os avanços tecnológicos existentes na Sociedade Contemporânea detêm um reflexo paradoxal; tanto acrescem qualidade de vida às pessoas, quanto são capazes de gerar prejuízos (desconhecidos) à saúde e ao meio ambiente. As nanopartículas são muito pequenas, medindo menos de um centésimo de bilionésimo de metro, são regidas por leis físicas muito diferentes daquelas com as quais a ciência está acostumada, assim existem probabilidades de apresentarem grau de toxicidade maior do que as partículas em tamanhos maiores, podendo ocasionar 
danos futuros aos pesquisadores, trabalhadores e consumidores. Há uma estreita relação entre o meio ambiente do trabalho e a saúde do trabalhador, sendo fundamental que se proporcionem condições para que este exerça sua atividade sem prejuízos à sua saúde. Ao Direito cabe criar alternativas de regulação à aplicação adequada dos princípios da dignidade da pessoa humana, da informação e da precaução em relação aos riscos criados pelo uso das nanotecnologias. Propõe-se uma alternativa de solução para a aplicação do princípio da precaução nas decisões relativas aos riscos das nanotecnologias, perpassada pela ética, visando à proteção da dignidade humana, e o diálogo entre as diferentes fontes do Direito, sempre filtradas pelo arcabouço normativo-principiológico-axiológico contido na Constituição Federal.

Palavras-chave: nanotecnologia, saúde, trabalhador, riscos, precaução.

Key-words: nanotechnology, health, worker, risk, precautionary.

\section{Introdução}

A nanotecnologia é o conjunto de ações de pesquisa, desenvolvimento e inovação que é obtida graças às especiais propriedades da matéria organizada a partir de estruturas de dimensões nanométricas. Atualmente existe uma necessidade de alerta do direito no que se refere aos riscos à saúde do trabalhador decorrentes da aplicação das nanotecnologias em escala industrial. A relação entre o Direito e os avanços nanotecnológicos é muito recente, mas absolutamente necessária, embora, na prática e na teoria, ainda seja muito tímida. A área jurídica continua imersa numa tradicional "tranqüilidade" de enfrentamento dos novos direitos e deveres que surgem diariamente.

O princípio da precaução deverá ser aplicado nas decisões concernentes aos riscos das nanotecnologias, fundamentado na melhor técnica disponível, tendo, ainda, como eixo básico a ética, visando à proteção da dignidade humana.

O Direito precisa encontrar formas de promover a aplicação do princípio da precaução nas decisões relativas aos riscos das nanotecnologias, e uma destas maneiras é através do diálogo entre as fontes do Direito, perpassando sempre pelo filtro da Constituição Federal.

As novas tecnologias devem gerar desenvolvimento e não danos à saúde, e, para tanto, há necessidade de se promover a inovação no Direito, de modo a permitir que seja possível evoluir sem causar maiores prejuízos ao planeta e aos seus 
habitantes, significando ainda, a aplicação da tendência mundial de focar o meio ambiente e a humanidade como centro dos sistemas jurídicos.

\section{Nanotecnologia e seus riscos à saúde}

A expressão "nanotecnologia" deriva do prefixo grego "nános", que significa anão, "techne" que equivale a ofício, e "logos" que expressa conhecimento.

A nanotecnologia é hoje um dos principais focos das atividades de pesquisa, desenvolvimento e inovação em todos os países industrializados. Os nanomateriais são utilizados nas mais diversas áreas de atuação humana, podendo-se destacar as seguintes áreas: cerâmica e revestimentos, plásticos, agropecuária, cosméticos, siderurgia, cimento e concreto, microeletrônica, e, na área da saúde, possuem aplicação tanto na odontologia quanto na farmácia (especialmente em relação à distribuição de medicamentos dentro do organismo), bem como em inúmeros aparelhos que auxiliam o diagnóstico médico (Brasil, ABDI, 2011, p. 11). Estima-se que de 2010 a 2015, o mercado mundial para materiais, produtos e processos industriais baseados em nanotecnologia será de US\$1 trilhão (Martins, 2007, p. 56).

Embora neste momento, os benefícios da nanotecnologia se sobreponham aos riscos, pelo menos por parte da mídia, o potencial desta tecnologia para resultados indesejáveis na saúde humana e no meio ambiente não deve ser menosprezado. O conhecimento das características das substâncias em tamanho maior não fornece informações compreensíveis sobre suas propriedades no nível nano, uma vez que as mesmas propriedades que alteram as características físicas e químicas das nanopartículas podem também provocar consequências não pretendidas e desconhecidas quando em contato com o organismo humano.

A ausência de estudos sobre a interação da aplicação das nanotecnologias com o meio ambiente (ar, água e solo) expõe a possibilidade de ocorrência de riscos ambientais e também riscos em relação aos seres humanos. ${ }^{1}$ Alguns testes com

\footnotetext{
${ }^{1}$ Com o objetivo de discutir os impactos da nanociência na sociedade, no meio ambiente e na saúde humana, pesquisadores e ativistas fundam o primeiro Observatório de Nanotecnologias das Américas, na Cúpula dos Povos, evento paralelo à Rio+20. No encontro, o médico William Waissmann, do Programa de Pós-graduação em Saúde Pública e Meio Ambiente da Fundação Oswaldo Cruz,
} 
animais demonstraram danos cerebrais, relacionados à coagulação sanguínea, danos em trato respiratório e também alterações na embriogênese (Grupo ETC, 2005, p. 22).

Pesquisas já demonstraram que camundongos que receberam nanotubos de carbono desenvolveram lesões biológicas semelhantes àquelas provocadas por inalação de amianto. O foco de atenção não são apenas as descobertas na escala nano, mas também as repercussões que essas pesquisas gerarão na natureza e os modos como elas atingirão a vida humana no planeta. Como se pode verificar, o problema não são as descobertas em si, mas os seus reflexos na vida das pessoas e na estrutura do planeta (Engelmann, 2010 a, p. 255).

A maioria dos testes com nanopartículas tem sido desenvolvida em laboratório, e um problema especialmente grave é que investigações voltadas unicamente a substâncias tóxicas isoladas jamais podem dar conta das concentrações tóxicas no ser humano. Aquilo que pode parecer "inofensivo" num produto isolado talvez seja consideravelmente grave no "reservatório do consumidor final" (Beck, 1992, p. 31). As publicações científicas quanto aos riscos estão restritas aos componentes dos produtos, e não aos produtos acabados, que serão apresentados para o consumo, o que gera um sinal de alerta, pois é neste momento, quando o produto é consumidor, que passa a sofrer novos e diferentes processos de interação (Engelmann, 2011 b, p. 34).

Hoje, em relação ao uso de produtos que contenham partículas nanoengenheiradas, há mais perguntas do que respostas (Buzby, 2010, p. 530). Os impactos nocivos e riscos potenciais à saúde humana e animal, ao meio ambiente e até em relação ao comportamento humano são ainda pouco conhecidos (Brasil, ABDI, 2010, p. 40). Para a avaliação desses aspectos, deverão ser aperfeiçoados e desenvolvidos testes, buscando identificar: “(i) suas propriedades físico-químicas; (ii) seu potencial de degradação e de acumulação no meio ambiente; (iii) sua toxicidade

mencionou que o maior desafio no momento é que as agências regulatórias desenvolvam rotinas de avaliação para produtos em escala nanométrica e citou um dado estatístico que o preocupa: "para cada 38 trabalhos científicos dedicados ao estudo e desenvolvimento de novos nanoprodutos, temos somente um trabalho com o objetivo de avaliar questões de segurança e toxicidade" (Kugler, 2013). 
ambiental: e (iv) sua toxicidade com relação aos mamíferos" (Brasil, ABDI, 2010, p. 41).

As questões-chaves na área de nanomateriais incluem a falta de dados sobre os impactos na saúde, o potencial de toxicidade ambiental e uma incapacidade de continuar a monitorar quaisquer efeitos adversos. A falta de tecnologias e protocolos para monitoramento ambiental e de saúde, detecção e remediação é ainda muito grande e deve ser considerada, apesar de alguns esforços que estão sendo feitos para resolver o problema. No entanto existe também uma falta coordenada de informações a disposição do público sobre os produtos com nanotecnologia, incluindo onde estão sendo produzidos e usados, bem como acerca dos riscos potenciais que podem existir (Senjen, 2009). Neste sentido, a questão dos riscos decorrentes das aplicações das nanotecnologias permeia toda a comunidade científica que se dedica ao assunto.

\section{Gestão de risco, precaução e meio ambiente do trabalho:}

A gestão destes riscos envolve a prevenção e a precaução, sendo que a prevenção lida com previsão, e, a precaução atua em situações de riscos sem base comprobatória segura. Quanto ao Princípio da Precaução, havendo a incerteza cientifica acerca das consequências de determinada atividade ou tecnologia, a cautela deverá ser a diretriz de conduta.

Conforme Engelmann, Flores e Weyermüller, os parâmetros do princípio da precaução são:

Equacionar a possibilidade do surgimento de perigo de dano grave ou irreversível e a inexistência de certeza quanto ao efetivo controle cientifico das consequências da pesquisa em relação ao meio ambiente e também ao ser humano. Estes são os parâmetros do principio da precaução (Engelmann \& Flores, 2010, p. 125-126).

A precaução estabelece um padrão de prova menos exigente, mais amplo e orientado contextualmente para a gravidade de risco (Carvalho, 2011, p. 49). É em nome do princípio da precaução que se pode, por exemplo, no caso das nanotecnologias, estabelecer que sejam efetuados estudos prolongados no tempo, para que sejam produzidos dados mais confiáveis acerca dos riscos e efeitos. As 
pesquisas sobre os impactos das nanoparticulas no meio ambiente estão apenas no início e é o caso de se aplicar o principio da precaução e exigir que sejam desenvolvidas de forma concomitante pesquisas que levem a inovações tecnológicas advindas da nanotecnologia e a pesquisas toxicológicas devido ao uso e disposição destas nanoparticulas nos ecossistemas naturais (Martins et al., 2007, p. 295). A cautela deverá ser a diretriz seguida frente às incertezas científicas.

A adoção do princípio da precaução não pode autorizar a moratória completa das pesquisas e usos das nanotecnologias, não pode ocorrer simplesmente a interrupção pura das pesquisas (Engelmann, 2010 b). Para adotá-lo é necessária cautela e fundamentação. O princípio da precaução deve fazer parte da esfera civil do século XXI, mas de forma equilibrada e sem perder de vista os princípios de razoabilidade e de proporcionalidade. O perigo está no radicalismo em sua adoção que só conduzira à estagnação do progresso cientifico e tecnológico (Lopez, 2010, p. 109).

O princípio da precaução não é um motivo de estagnação ou bloqueio do desenvolvimento científico, mas, pelo contrário, uma fonte de progresso científico. É um princípio de justiça no sentido clássico, racional e comprometido com o futuro (Aragão, 2002, p. 16). E deve ser amplamente aplicado também em relação ao meio ambiente do trabalho.

Compreende-se como meio ambiente do trabalho todas as condições internas e externas do local de trabalho e a sua relação com a saúde dos trabalhadores. E, cabe salientar, um ambiente de trabalho seguro e compatível com a condição de pessoa humana é um direito fundamental do trabalhador. ${ }^{2}$ No meio ambiente do trabalho a aplicação do princípio da precaução é encontrada em todas as situações de incerteza sobre a potencialidade danosa de determinado produto químico ou biológico cujo conhecimento sobre possíveis efeitos toxicológicos sobre a saúde

\footnotetext{
${ }^{2} \mathrm{O}$ meio ambiente laboral, quando considerado como interesse de todos os trabalhadores em defesa de condições da salubridade do trabalho, ou seja, o equilíbrio do meio ambiente do trabalho e a plenitude da saúde do trabalhador, constituem direito essencialmente difusos, inclusive porque a sua tutela tem por finalidade a proteção da saúde, que sendo direito de todos, da coletividade, caracteriza-se como um direito eminentemente metaindividual. A proteção ao meio ambiente do trabalho associa-se à tutela da saúde do trabalhador, sob o fundamento constitucional da tutela da vida com dignidade (Rocha, 1997, p. 32).
} 
humana e o meio ambiente ainda é precário. Nessa situação, a aplicação do princípio da precaução recomenda a não exposição dos trabalhadores a tais agentes (Engelmann, Flores \& Weyermüller, 2010, p. 208).

A Constituição Federal em seu artigo 200, entre as competências do Sistema Único de Saúde (SUS), elenca a colaboração na proteção do meio ambiente, nele compreendido o do trabalho. Existe uma estreita relação entre o meio ambiente do trabalho e a saúde do trabalhador, sendo necessário que este possua condições para exercer sua atividade sem prejuízos a sua saúde. O meio ambiente de trabalho é um determinante social de saúde.

A Lei n. 8.080, de 1990, (Lei Orgânica da Saúde) menciona uma tutela e colaboração na proteção ao meio ambiente do trabalho e na saúde do trabalhador. $\mathrm{O}$ artigo $3^{\circ}$ da Lei Orgânica da Saúde estabelece que a saúde tem como fatores determinantes e condicionantes, entre outros, a alimentação, a moradia, o saneamento básico, o meio ambiente, o trabalho, a renda, a educação, o transporte, o lazer e o acesso aos bens e serviços essenciais; os níveis de saúde da população expressam a organização social e econômica do País. A Lei n. 8.080 nos seus artigos 16,17 e 18 considera a saúde um direito fundamental e objetiva das condições de implementação à ela, por intermédio de ações e serviços que englobam nas três esferas da administração, o ambiente do trabalho e as saúde do trabalhador. Ainda, a convenção número 155 da OIT que trata de segurança e saúde dos trabalhadores utiliza a expressão meio ambiente de trabalho reiteradas vezes e a ementa desta convenção refere-se a segurança, saúde dos trabalhadores e o meio ambiente de trabalho. E o artigo $3^{\circ}$ trata saúde como não só a aus ência de afecções ou doenças, mas também os elementos físicos e mentais que afetam a saúde e estão diretamente relacionados com a segurança e a higiene no trabalho. Ainda, conforme preconiza o artigo $7^{\circ}$ da Constituição Federal do Brasil, "são direitos dos trabalhadores urbanos e rurais, além de outros que visem à melhoria de sua condição social; inciso XXII". "Redução dos riscos inerentes ao trabalho, por meio de normas de saúde, higiene e segurança".

Concomitantemente ao princípio da precaução, segue o direito à informação como um dos instrumentos mais necessários a serem aplicados no meio ambiente do trabalho, uma vez que os trabalhadores devem saber a que condições estão expostos 
durante seu labor. O princípio da informação é corolário do princípio da participação e pressuposto para a implementação do princípio da precaução, e está presente em praticamente todas as mais recentes Convenções da OIT, bem como na legislação ambiental laboral.

Percebe-se, no entanto, que, em relação às nanotecnologias, o princípio da informação não vem sendo aplicado, uma vez que muitas empresas já estão trabalhando em suas linhas de produção com produtos potencialmente perigosos, sem que os trabalhadores saibam acerca da situação. Uma exceção a esta regra é a Convenção Coletiva dos trabalhadores na indústria farmacêutica de São Paulo, que após três anos de negociação, foi inserida uma cláusula sobre nanotecnologia, e a expectativa para este ano é estender essa conquista para todo o setor químico do Estado. $^{3}$

A preocupação com a saúde do trabalhador, através do enfoque tranbsdisciplinar para a melhoria do ambiente laboral, é uma das maneiras de aplicação do princípio da dignidade da pessoa humana, entendendo os direitos do trabalhador como direitos de cidadania, que devem ser priorizados em relação aos valores econômicos. O objetivo principal da proteção à saúde dos trabalhadores é buscar a efetividade dos princípios fundamentais da República Federativa do Brasil, embasados na garantia da dignidade humana, do respeito ao meio ambiente e aos valores sociais e humanos do trabalho, bem como no respeito à cidadania. E, significa, ainda, a aplicação da tendência mundial de focar o homem como centro dos sistemas jurídicos.

Assim, apesar das incertezas sobre as consequências de determinadas atividades, o Direito não pode se abster de tutelar os interesses das futuras gerações em relação às qualidades ambientais necessárias a uma existência digna, sob pena de negar a sua função de construção de um futuro desejado (Carvalho, 2007, p. 77). A relação entre o Direito e os avanços nanotecnológicos na América Latina é muito

${ }^{3}$ Cláusula oitava - Nanotecnologia. A empresa garantirá que os membros da CIPA e do SMET sejaminformados quando da utilização de nanotecnologia no processo industrial. A CIPA, o SMET e os trabalhadores terão ainda acesso a informações sobre riscos existentes a sua saúde e as medidas de proteçãoa adotar (Fetquim, 2013). 
recente, mas absolutamente necessária. ${ }^{4} \mathrm{~A}$ área jurídica continua imersa numa tradicional "tranquilidade" de enfrentamento dos novos direitos e deveres que surgem diariamente.

\section{Nanotecnologia e o direito inseridos na transdisciplinaridade para equacionar os riscos}

A busca das respostas aos desafios surgidos em função do uso e aplicação das novas tecnologias envolverá, necessária e impreterivelmente, diferentes áreas do conhecimento, mas sempre guiadas pelos princípios constitucionais, colocando a proteção do homem e do meio ambiente como prioridade (Engelmann, Flores \& Weyermüller, 2010, p. 131). As áreas técnicas (ciências duras) envolvidas deverão valer-se das Ciências Humanas (ciências brandas), dentre as quais o Direito, para fazer a ponte entre as investigações na escala nano e o destinatário final, que são as pessoas (Engelmann, Flores \& Weyermüller, 2010, p. 129-130).

O Direito ainda não se estruturou adequadamente para responder aos desafios propostos pelas novas tecnologias. O Direito é mais devagar quanto à legitimação das inovações cientificas, ${ }^{5}$ bem como quanto aos seus efeitos no meio ambiente e na saúde. Isso porque o Direito temporaliza a sua complexidade por processos administrativos ou jurisdicionais (Carvalho, 2011).

Desta forma, cabe ao Direito, como ciência, possibilitar a criação de instrumentos jurídicos com objetivo de efetivar medidas de gerenciamento preventivo

\footnotetext{
${ }^{4}$ No site http://nanotech.law.asu.edu/?rgn=cfr verifica-se a total ausência de regulação específica acerca das nanotecnologias em qualquer país da América do Sul, enquanto que, nos Estados Unidos há documentos que datam desde 2004 (Nanomaterials: Potential Risks and Safe Handling Methods, produzido pela Pensylvania State University), com grande crescimento no número de documentos a partir de 2008. Ainda, neste site, chama a atenção o documento da Agência Americana de Meio Ambiente (EPA) chamado Regulatory Plan na Semiannual Regulatory Agenda, de 2009. Duas vezes por ano EPA publica sua Agenda Semestral de regulamentação, que detalha as prioridades planejadas para o próximo ano. Neste documento, a EPA anunciou como prioridades pesquisas para determinar os efeitos de certos nanotubos de carbono de parede múltipla e argilas nanométricos e alumina sobre a saúde. Tal regra seria proposta em novembro de 2010, exigindo que os fabricantes desenvolvessem testes para avaliação de saúde e apresentassem os dados para o EPA.

${ }^{5}$ As nanotecnologias movem-se por vezes em "zonas cinzentas" do ponto de vista teórico, mas, sobretudo, em "zonas cinzentas" do ponto de vista jurídico. É preciso regulamentar a introdução dos produtos no mercado e adotar regras de rotulagem dos produtos de consumo, tendo em vista a proteção das pessoas e do ambiente (Schlyter, 2009, p. 16-17).
} 
do risco, baseado nos princípios da prevenção, da precaução, da responsabilização, da informação e da sustentabilidade, objetivando sempre o cuidado com o ser humano e o meio ambiente.

Quanto à regulação, verifica-se que o desafio imposto pela realidade das nanotecnologias aos juristas exige respostas quanto ao estabelecimento de limites e para solução de conflitos que venham a surgir. O direito precisa desta evolução, sob pena de, mais uma vez, ficar um ou vários passos atrás das transformações que ocorrem no mundo e nas demais áreas do conhecimento. O modelo jurídico em vigor no Brasil (liberal-individualista) não tem se mostrado capaz de recepcionar e solucionar as novas demandas sociais, portadoras de "novos" direitos, se fazendo necessária a proposição de novos instrumentos jurídicos, que sejam mais flexíveis, mais ágeis, capazes de regular estas novas e complexas situações.

O pluralismo de fontes passa a ser uma das alternativas frente à necessidade de evolução do Direito, para capacitar-se a lidar com os desafios surgidos das novas tecnologias, entre elas, as nanotecnologias. A lei é incapaz de prever todos os casos concretos, mas isso não significa que as situações não previstas deixam de reclamar uma solução conforme o direito. Um dos desafios é aprender a pluralidade das fontes, vencendo o reducionismo codificador.

As leis não conservam indefinidamente seu alcance original, uma vez que tudo no mundo evolui e muda, assim surgem novas questões ou as questões daquele momento de criação da lei já mudaram, por isso, especialmente em relação às novas tecnologias, não parece ser uma das melhores possíveis respostas do direito, a simples criação legislativa. Uma nova tecnologia fruto da grande revolução tecnológica atual também precisa de um novo modo, meio de regulamentação, diferente do tradicional e letárgico modelo de regulamentação legal (por meio de leis). O Direito não está todo na lei, da mesma forma que a lei não contém nem todo o Direito, tampouco toda a Justiça.

A consideração da lei como principal fonte do Direito precisa ser revista, especialmente porque a lei sempre olha para o passado, um tempo incompatível com as novas tecnologias (Engelmann, 2011 b, p. 351). As nanotecnologias exigirão uma nova Teoria das Fontes do Direito, que promova um efetivo diálogo entre todas elas, 
sem uma hierarquia, mas canais de comunicação e complementação conteudísticos (Engelmann \& Berger Filho, 2010, p. 82). Por este modelo, onde as fontes (nacionais e internacionais $)^{6}$ estarão uma ao lado da outra, podendo conjugar contribuições para a adequada resolução do caso concreto, o que se pretende é o trabalho conjunto das fontes do Direito, movimentando-se horizontalmente, com caminho de passagem obrigatório pelo centro, onde estará a Constituição da República (Engelmann, 2011 b, p. 352).

O diálogo entre as fontes é o diálogo entre leis postas, podendo também envolver normas narrativas de inspiração, soft Law, costumes, princípios gerais, reconhecendo a força dos princípios imanentes do sistema e do bloco de constitucionalidade, além de diretrizes e estudos desenvolvidos por um grande conjunto de organismos internacionais, como a ISO, OCDE, NIOSH, OSHA, ANSI, CEN, ASTM, IEEE, entre outros. A técnica trabalha com a aplicação simultânea e coordenada das diferentes fontes legislativas (leis especiais e leis gerais, de origem nacional e internacional). Resta demonstrado que são muitos os modos de produção do Direito (fontes) e que o centro de produção deslocou-se do Estado (antes único produtor) para vários outros locus da sociedade nacional e internacional, adequando assim a ciência do Direito às grandes transformações introduzidas pelas novas tecnologias, que esperam respostas legais às novas situações surgidas. Importante destacar que entre os espaços atuais produtores das fontes do Direito, estão as organizações, principalmente as empresariais, produtoras de diretrizes e normas técnicas, adequadas às inovações nanotecnológicas (Engelmann, 2012 b, p. 330).

Ao utilizar-se o Diálogo das fontes, os marcos normativos e as respostas jurídicas produzidos deverão considerar a contribuição de cada uma das fontes, através de um filtro dos controles de constitucionalidade e convencionalidade, ${ }^{7}$

\footnotetext{
6 "Assim, será possível colocar o Direito na rota de construção de uma sociedade onde o ser humano e o meio ambiente efetivamente sejam protegidos, por meio de um conjunto normativo moderno, flexível e em condições de viabilizar a comunicação do Direito nacional com a sua interface internacional e vice-versa, cada vez mais importante, especialmente no caso da construção dos marcos regulatórios para as nanotecnologias." (Engelmann, 2011 a, p. 36).

7 O controle de convencionalidade concentrado ou abstrato, surgiu em 2004, com o advento da Emenda Constitucional no ${ }^{\circ}$, que veio possibilitar que os tratados internacionais de direitos humanos - após aprovação com um quorum qualificado - passassem de um status materialmente constitucional
} 
visando sempre à proteção dos seres humanos e do meio ambiente (Engelmann, 2012 a, p. 140). Através do diálogo entre as fontes, passando a resposta pelos dois controles (constitucionalidade e convencionalidade), a rede de produção plural do direito atua, produzindo a substituição do modelo piramidal, com a Constituição no topo, por um desenho horizontal, onde a Constituição e os Tratados Internacionais e Convenções (especialmente os que versam sobre Direitos Humanos) estão no centro do sistema.

Assim, o diálogo entre as fontes parece ser um modo de aplicação da necessária transdisciplinariedade, internamente à Ciência do Direito, para a construção de respostas possíveis aos novos questionamentos surgidos devido aos riscos das novas tecnologias. A falta de certeza e a necessidade do Direito ter de aprender a lidar com isso e de ser capaz de fornecer as respostas necessárias à nova realidade também fortalecem o diálogo entre as fontes como alternativa possível.

Frente ao desafio de criar formas de operacionalizar a aplicação do Direito diante dos riscos das nanotecnologias, obedecendo sempre ao preceito constitucional de respeito à dignidade da pessoa humana, o diálogo entre as fontes torna-se uma opção muito palpável. A possibilidade de uso de diferentes fontes do Direito, sempre as passando pelo controle de constitucionalidade (através da filtragem no arcabouço normativo-principiológico-normativo contido na Constituição Federal) e de convencionalidade, parece ser uma resposta adequada à questão das nanotecnologias e seus riscos, especialmente pela possibilidade de usar fontes dos diferentes ramos do direito que se entrelaçam, cada um contribuindo com seus conhecimentos específicos.

\section{Considerações finais}

para uma condição (formal) de tratados equivalentes às emendas constitucionais.Seja qual for o modelo considerado é certo que os atos legislativos, administrativos e judiciais, atualmente, devem se submeter ao duplo limite vertical material de compatibilidade, de maneira que toda a ação estatal venha a observar não apenas a Constituição, mas, também, os tratados internacionais de direitos humanos (como primeiro limite), bem como os tratados internacionais comuns em vigor no país (como um segundo limite) (Mazzuoli, 2009, p. 367). 
A falta de informações sobre os efeitos das nanotecnologias na saúde e no meio ambiente é o argumento base para a adoção do princípio da precaução que é necessariamente voltado para o futuro, próximo ou longínquo, permitindo a aplicação de dois conceitos conhecidos do sistema jurídico: a prudência e a responsabilidade.

Deste modo, a garantia de um meio ambiente ecologicamente adequado, na sua íntegra, ou seja, incluindo deste modo saúde humana e saúde do ecossistema, não é apenas uma necessidade de garantia e implementação de direitos, mas também uma obrigação ética, dos seres humanos para com os seus próprios pares, membros todos de uma mesma coletividade.

As novas tecnologias devem gerar desenvolvimento e não ocasionar danos à saúde humana e ambiental, e, isso somente será possível ocorrendo inovação no Direito, por meio do diálogo entre as fontes do Direito, perpassando, como em um filtro, pelo arcabouço normativo-principiológico-axiológico contido na Constituição Federal e pelo controle de Convencionalidade.

Ainda, o uso das diferentes fontes do Direito, nacionais e internacionais, de origem no Estado e em outros atores, permitirá que o Direito trate adequadamente as demandas provenientes desta nova revolução tecnocientífica, não permanecendo estagnado à espera de um marco regulatório tradicional, fortemente vinculado e embasado na lei, com conceitos fixos e inadequados à velocidade de transformação e ampliação dos conhecimentos nas áreas das ciências duras, especialmente em relação às nanotecnologias.

\section{Referências}

ARAGÃO, Alexandra. Direito comunitário do ambiente. Coimbra: Almedina, 2002.

BECK, Ulrich. Risk society: towards a new modernity. London: Sage, 1992.

BRASIL. Agência Brasileira De Desenvolvimento Industrial (ABDI). Nanotecnologias: subsídios para a problemática dos riscos e regulação. Brasília: ABDI, 2011.

BRASIL. Agência Brasileira De Desenvolvimento Industrial (ABDI). Estudo prospectivo nanotecnologia. Brasília: ABDI, 2010.

BUZBY, Jean C. Nanotechnology for food applications: more questions than answers. The Journal of Consumer Affairs, Nova Yorque, 44(3):528-545, 2010. 
CARVALHO, Delton Winter de. As novas tecnologias e os riscos ambientais. In: LEITE, José Rubens Morato; FAGÚNDEZ, Paulo Roney Ávila (Org.). Biossegurança e Novas Tecnologias na Sociedade de Risco: aspectos jurídicos, técnicos e sociais. Florianópolis: Conceito, 2007. Relatório sobre aspectos regulamentares dos nanomateriais (2008/2208 (INI)) Comissão do Ambiente, da Saúde Publica e da Segurança Alimentar. [on line] Disponível em:http://www.europarl.europa.eu/sides/getDoc.do?pubRef=-

//EP//NONSGML+REPORT+A6-2009-0255+0+DOC+PDF+V0//PT.

CARVALHO, Delton Winter de. A construção probatória para a declaração jurisdicional da ilicitude dos riscos ambientais. Revista da AJURIS, 8:33-62, 2011.

ENGELMANN, Wilson. As nanotecnologias, os direitos humanos e o ensino jurídico: a dialética da "pergunta e resposta" como condição de possibilidade para construir o caminho em direção ao diálogo entre as fontes do direito. In: CARVALHO, Evandro Menezes de [et al.] (Org.). Representações do professor de Direito. 1 ed. Curitiba:CRV, 2012(a).

ENGELMANN, Wilson. O diálogo entre as fontes do direito e a gestão do risco empresarial gerado pelas nanotecnologias: construindo as bases à juridicização do risco. In: STRECK, Lenio Luiz; ROCHA, Leonel Severo; ENGELMANN, Wilson (Org.). Constituição, Sistemas Sociais e Hermenêutica, Anuário do Programa de PósGraduação em Direito da UNISINOS. Porto Alegre: Livraria do Advogado Editora Ltda, v. 9, 2012(b).

ENGELMANN, Wilson. As Nanotecnologias e a Propriedade Intelectual: desafios e possibilidades à gestão transdisciplinar da inovação. In: BOFF, Salete Oro; PIMENTEL, Luis Otávio (Org.). A Proteção Jurídica da Inovação Tecnológica. v. 1. (1. ed.) Passo Fundo: EdIMED, 2011 (a).

ENGELMANN, Wilson. Os avanços nanotecnológicos e a (necessária) revisão da teoria do fato Jurídico de Pontes de Miranda: compatibilizando "riscos" com o "direito à informação" por meio do alargamento da noção de "suporte fático" In: STRECK, Lenio Luiz; MORAIS, José Luís Bolzan de; ROCHA, Leonel Severo (Orgs.). Constituição, sistemas sociais e hermenêutica. Anuário do Programa de Pós Graduação em Direito da Unisinos: Mestrado e Doutorado. Porto Alegre: Livraria do Advogado, v.8, 2011 (b).

ENGELMANN, Wilson. A nanotecnologia como uma revolução científica: os direitos humanos e uma (nova) filosofia na ciência. In: STRECK, Lenio Luiz; MORAIS, José Luís Bolzan de (Org.). Constituição, sistemas sociais e hermenêutica. Anuário do Programa de Pós Graduação em Direito da Unisinos: Mestrado e Doutorado. Porto Alegre: Livraria do Advogado, 2010 (a).

ENGELMANN, Wilson. As nanotecnologias e a Inovação Tecnológica: a "hélice quádrupla" e os Direitos Humanos. In: ENGELMANN, Wilson. Nanotecnologias: um desafio para o Século XXI. v. 1. [CD] São Leopoldo: Casa Leria, 2010 (b). p. 148-189. 
ENGELMANN, Wilson. A (re)leitura da Teoria do Fato Jurídico à luz do "Diálogo entre as Fontes do Direito": abrindo espaços no Direito Privado constitucionalizado para o ingresso de novos direitos provenientes das nanotecnologias. In: STRECK, Lenio Luiz; ROCHA, Leonel Severo; CALLEGARI, André Luís. (Org.). Constituição, Sistemas Sociais e Hermenêutica, Anuário do Programa de Pós-Graduação em Direito da UNISINOS. v. 7. Porto Alegre: Livraria do Advogado Editora Ltda., 2010 (c). ENGELMANN, Wilson e BERGER FILHO, Airton Guilherme. As nanotecnologias e o direito ambiental: a mediação entre custos e benefícios na construção de marcos regulatórios. Revista de Direito Ambiental, São Paulo, 59:50-91, 2010.

ENGELMANN, Wilson e FLORES, André Stringhi e WEYERMÜLLER, André Rafael. Nanotecnologias, Marcos Regulatórios e Direito Ambiental. Curitiba: Honoris Causa, 2010.

FETQUIM. Setor Farmacêutico. Termo aditivo à convenção coletiva de trabalho. FETQUIM-CUT 2012-2013 [on line] Disponível em: $<$ www.sindusfarma.org.br/informativos/Aditivo_Campinas_2012.pdf $>$. Acesso em 20 jun. 2013.

GRUPO ETC. Nanotecnologia: os riscos da tecnologia do futuro: saiba sobre produtos invisíveis que já estão no nosso dia-a-dia e o seu impacto na alimentação e na agricultura. Tradução de José F. Pedrozo e Flávio Borghetti. Porto Alegre: L\&PM, 2005.

KUGLER, Henrique. Nanotecnologia em debate. Ciência hoje. 2012. [on line] Disponível em: http://cienciahoje.uol.com.br/blogues/bussola/2012/06/nanotecnologiaem-debate. Acesso em 10 jun. 2013.

LOPEZ, Teresa Ancona. Princípio da precaução e evolução da responsabilidade civil. São Paulo: Quartier Latin, 2010.

MARTINS, Paulo Roberto (coord.) [et al]. Revolução invisível: desenvolvimento recente da nanotecnologia no Brasil. São Paulo: Xamã, 2007.

MAZZUOLI, Valério de Oliveira. O Controle Jurisdicional da Convencionalidade das Leis. São Paulo: Revista dos Tribunais, 2009.

MORRIS, Julian. Defining the precautionary principle. In: MORRIS, Julian (Ed.). Rethinking risk and precautionary principle. Oxford: Buttrtworth-Heinemann, 2002.

ROCHA, Julio César de Sá da. Direito Ambiental e Meio Ambiente do Trabalho: dano, prevenção e proteção jurídica. São Paulo: LTr, 1997.

SCHLYTER, Carl. Relatório sobre aspectos regulamentares dos nanomateriais (2008/2208(INI)). Comissão do Ambiente, da Saúde Publica e da Segurança Alimentar. 2009 [on line] Disponível em:http://www.europarl.europa.eu/sides/getDoc.do?pubRef=- 
Anais dos III Congresso Iberoamericano de Direito Sanitário / II Congresso Brasileiro de Direito Sanitário

//EP//NONSGML+REPORT+A6-2009-0255+0+DOC+PDF+V0//PT . Acesso em 20 jun. 2013. p. 16-17.

SENJEN, Rye. Nano and biocidal silver: extreme germ killer present a growing threat to public health. 2009 [on line] Disponível em: $<$ http://nano.foe.org.au/sites/default/files/Nanosilver\%20Report\%202009.pdf>. Acesso em: 20 jun.2013. 